Original Research Paper

\title{
An Enhancement of Dyslexic Mobile Application using Sight Word Reading Strategy: Results and Findings
}

\author{
Noor Hazlini Borhan, Cheah Wai Shiang, Po-Chan Chiu, \\ Hamizan Sharbini, Tan Ping Ping, Rosita Mohamed Othman and Marcella Peter
}

Faculty Computer Science and Information Technology, Universiti Malaysia Sarawak, Kota Samarahan, Sarawak, Malaysia

\author{
Article history \\ Received: 15-11-2017 \\ Revised: 22-03-2018 \\ Accepted: 12-05-2018 \\ Corresponding Author: \\ Po-Chan Chiu \\ Faculty Computer Science and \\ Information Technology, \\ Universiti Malaysia Sarawak, \\ Kota Samarahan, Sarawak, \\ Malaysia \\ Email: pcchiu@unimas.my
}

\begin{abstract}
Dyslexia is an indicating term for learning disorder due to the difficulty in identifying speech and sound of letters and words, causing reading difficulty. Most children with dyslexia utilise the greater part of their senses to connect with their environment. One of the difficulties faced by dyslexic children is their troubles expressing their emotion or thought through verbal or written communication due to limited vocabulary, which is caused by issues in perceiving letters, sound and importance of the word overall. Sight word reading is a methodology with various reading stages and fascinating diversion with the purpose to create a fun reading experience. Currently, the dyslexia centre (i.e., Learning and Resource Centre, Dyslexia Association of Sarawak) does not adopt Information and Communication Technology (ICT) in their teaching and learning processes. Hence, in this study, a mobile application that utilises sight word reading strategy has been produced with the aim to help children with dyslexia build up their reading aptitudes. Sight words reading strategy is incorporated into three different modules in the mobile application, namely short stories, rhymes and song verses, according to the suggestions given by the instructors at dyslexia centre. This paper presents the study on the effect of sight word reading strategy in mobile application. The main contributions of this study is the utilisation of sight word reading strategy to enhance the application features such as story, rhyme and song modules. An improved score board is added to monitor the progress of the child. This mobile application, Mr Read V2.0 has been tested at the Learning and Resource Centre, Dyslexia Association of Sarawak with the instructors and dyslexic children, together with their parents. The children obtained $28 \%$ improved test scores taken before and after using Mr. Read V2.0. The overall results of the testing session showed that $100 \%$ respondents, instructors, parents and children either agreed or strongly agreed that this mobile application can improve the reading skill from using the additional features added to Mr. Read V2.0. Sight word reading strategy that is incorporated into mobile application is an effective approach to help dyslexic children improve their reading skill.
\end{abstract}

Keywords: Dyslexia, Reading Skills, Sight Words, Mobile Application

\section{Introduction}

Dyslexia is a specific learning disability characterised by the inability to decode and recognise words which have been shown to originate from neurobiological (Lyon et al., 2003). Children with dyslexia utilize the greater part of their faculties to speak with their environment. They are effectively pulled in to images instead of words and are exceptionally inventive. Many individuals relate the words "learning inability" and "dyslexia" to the words "idiotic" or "unintelligent". This is in actuality the most remote clarification from reality. Dyslexia is really a trouble with language, not knowledge (Bouquett and Lindsey, 2008). Dyslexia is a weakness in the capacity to read (Farrell and Osenga, 2013). Instead, dyslexic individuals have difficulties 
with reading and spelling regardless of having the ability to learn. To overcome this difficulty, an appropriate learning approach should be carried out in order to fulfil this special learning needs. There are different ways to help dyslexic children build up their reading achievement for instances, repeated reading, sight word drills and syllable example (Fawcus, 2000; Griffin and Appel, 2016). Sight words give a fantastic establishment to reading (McArthur et al., 2013) as the higher the frequency the word appears to the child, the more likely he/she is ready to perceive and comprehend the importance of the word overall (Garg, 2016).

Currently, reading with dyslexic children requires assistance from adults and in most cases, is a one-to-one approach as an adult need to present flash cards to the child while reading. This can be time consuming and most of the children cannot practise reading independently. Furthermore, these special children have a very short span of attention which make reading even more challenging. Computer aided reading tool, for instance, a mobile application seems like a reasonable solution as it can be designed to be engaging and relatively easy for the children to handle on their own. However, dyslexic children have difficulty reading from white or glaring background (Meares, 1980) such as white paper or computer screen. This leads to a dire need for a mobile application that can assist dyslexic children in reading independently as current mobile applications for reading is designed for normal children.

The aim of this mobile application is to assist primary school children with dyslexia, aged 7 to 12 to increase their vocabulary size. The novelty in our mobile application is the integration of sight words approach. This is similar to how manual flash cards are presented when the children are reading but without the assistance from an adult. This promotes independent reading as the children have the freedom to listen to the words whenever they required. As our focus is on vocabulary size, in order to evaluate the effectiveness of our mobile application, the children are required to take quizzes in the form of game, before and after reading the stories with sighted words to observe how many of the words they can recall.

\section{Background}

This project, a mobile game-based learning application has been created for children with dyslexia to enhance their instructive learning. By utilizing smartphones, they can access the lessons effectively and rehearse at anyplace convenient. Multimedia elements are integrated into the mobile application to make the learning environment more attractive and interactive for this special group of children. The learning progression of dyslexic children is slower compared to normal children, causing them to barely comprehend and struggling to catch up in class. For the time being, the number of applications that is specially developed for dyslexic children is limited. Alghabban et al. (2017) proposed a customized mobile learning application using cloud computing technology to meet the needs of the children with dyslexia. The study shows that their learning capabilities has enhanced by using the mobile application. Samsudin (2017) has proposed a mobile application to measure dyslexia learning skills with multisensory approach and showed a satisfactory result. The study proven that interactive design such as rhythmic, voice output, songs, videos and animations plays an important role in the learning process for children with dyslexia. Apart from that, a research work proposed by Azmi et al. (2017) has developed a mobile application for children with dyslexia that emphasises on learning the alphabet in Malay language. The results show that interactive and multimodal mobile application encourages dyslexic children to become more focus during the learning session and their help them to improve.

The existing mobile applications that enforce reading skill for dyslexic children are mostly based on phonics awareness approach and sight words remain only to be used as manual flash cards to teach basic reading. Although story-based applications are currently available in the mobile application stores for normal children, some of the features are not suitable for children with dyslexia. For example, the font type and background colour used are not suitable for children with dyslexia. Furthermore, the Dyslexia Association of Sarawak Centre does not adopt Information and Communication Technology (ICT) in their teaching and learning processes. Rather, traditional flashcard method is used to introduce the new words to the children at that centre, triggering the initiative to develop an interactive mobile application.

\section{Methodology}

An earlier version of the mobile application, $\mathrm{Mr}$. Read V1.0 by Borhan et al. (2015), was developed and tested with the primary school students with dyslexia. The outcome shows that there are several enhancements required in order to consistently encourage and attract the dyslexic children using the mobile application to practise reading on their own. This leads to the enhancement in Mr. Read V2.0.

Like the previous version, the sight words used in Mr. Read V2.0 are based on Dolch's Sight List (Johnson, 1971). The Dyslexia Association of Sarawak Centre also have been using Dolch's list for teaching sight words. This made dyslexic primary school students become more familiar with the content of both versions of $\mathrm{Mr}$. Read mobile applications. The sight words are incorporated in short stories, rhymes and song verses in this mobile application. Besides that, a sight words quiz game has also been developed to test the children's 
understanding by providing the game scores that reflects their reading ability. Reading ability in this context means the ability to sound out, recognize and recall words.

Mr. Read V2.0 has been developed based on the suggestions and comments from the instructors working for the dyslexia centre. Mr. Read V2.0 has additional elements too, which have been re-tested in another separate session with the dyslexia primary school students at the Dyslexia Association of Sarawak centre. Table 1 shows the comparison between Mr. Read V1.0 and an enhanced version Mr. Read V2.0, which is the main contribution of this research study.

Mr. Read V2.0 adopts mobile Game-Based Learning (mGBL) engineering model (Shiratuddin and Zaibon, 2011), similar to the methodology used for Mr. Read V1.0. Storyboard. The major reason this model is chosen because it includes learning content design and development. Other than that, mGBL engineering model encourages the use of different game level and storyboard. Moreover, this methodology is suitable for this project as the phases can be customized according to the project needs.

The tool used to develop this Android mobile application is Android Studio software where the full JAVA codes are written. This tool requires JAVA SE Development Kit Version 7 (JDK7) plug in to enable the installation of appropriate API version. Only with the correct API installed, can the application run or debugging be performed. In this project, the target android platform is Android version 4.2.2. Therefore, API version 17 is used. The target device for this project is tablet as tablet has larger user interface which is more suitable for dyslexic children. This ensures that focus can be placed on the functionality of the proposed features to meet the project objectives.

Mr. Read V2.0 (refer to Proposed Solution section for the detailed implementation) is evaluated by dyslexic children, parents and teachers at Dyslexia Association of Sarawak. The first session is conducted with the dyslexic children, where they are required to take three sets of quiz in the form of game with each set of their scores recorded. For the first set, the students are required to take a quiz before opening the Story Module in Mr. Read V2.0. For the second set, the students take the quiz after they have read story from Mr. Read 2.0. Lastly, the students are tested again after reading two stories from Mr. Read V2.0. The scores are recorded after each quiz.

Lee (1999) recommended that to develop effective interactive multimedia software, the dimensions of usability testing to be considered are learnability; performance effectiveness; flexibility; error tolerance and system integrity; and user satisfaction. Therefore, three main evaluation criterions set for usability testing of this application are ease of use, user satisfaction of the user interface and multimedia components and efficiency in learning. Hence the questionnaire is designed to garner feedbacks from the children, parents and teachers regarding the ease of use, the appropriateness of the multimedia elements and the helpfulness of the learning contents for Mr. Read V2.0. In the questionnaire, there is a total of 10 questions and the respondents are required to rate according to the 5-Likert scale: 1 to 5 where 1(Strongly Disagree), 2(Disagree), 3(Neutral), 4(Agree) and 5(Strongly Agree).

In the second testing session, children, teachers and parents are free to explore the mobile application. Then, they are required to fill in the questionnaire on usability and provide their feedback on the mobile application. For the children, they are accompanied by an adult to help them complete the questionnaire. The outcome of the survey is presented in the Results and Findings section.

\section{Proposed Solution}

The following are the screenshots of Mr. Read V2.0 mobile application which have been implemented.

Figure 1 demonstrates the main menu of Mr. Read V2.0. There are three fundamental parts, namely particular instruction, background sound and modules. If further assistance is required, the user may click "Help" at any time and the guideline will be provided. The user can tap on the sound button to empower the background sound. There are four modules for user to pick, to be specific as "Story", "Rhyme", "Song" and "Game".

Figure 2 demonstrates the menu for Story Module. There are three different submodules/stories accessible through buttons for "Story 1", "Story 2" and "Story 3". For instance, the user may tap on the button "Story 3" and will be directed to the main page of Story 3 which appeared in Figure 3. If the user taps on the "Guideline" button (button with speaker image), he or she can listen to the title and story instruction. To begin reading the story, the user may tap the "Read Story" button.

Figure 4a demonstrates the first page of the Goldilocks and the Three Bears story. In this page, three sight words are highlighted as shown in the figure. The user can tap on any of the three sight words to learn how to spell and sound out the respective sight word. For an example, user tap "Once" and will lead the user to the popup box as shown in Figure 4(b). The user can tap on the button with speaker image to listen back to the sight word and the spelling. The user can tap on the " $\mathrm{X}$ " button to continue perusing the story.

Figure 5 demonstrates the menu in Rhyme Module. There are three distinctive submodules/rhymes that are accessible through the buttons "Rhyme 1", "Rhyme 2" and "Rhyme 3". For instance, the user may tap on the button "Rhyme 1" and subsequently lead the user to the first page of Rhyme 1 as shown in Figure 6. 
Table 1: Comparison between Mr. Read v1.0 and Mr. Read v2.0 mobile application

\section{Mr. Read V1.0 (Borhan et al., 2015)}

Normal font

Non-tapping on the Words

Limited module, only one module is provided for each story,

Rhyme and song

A game with score result that is shown based on the current session played by the user.
Mr. Read V2.0

OpenDyslexic textual fonts

Sound is produced when tapping on the words

Intermediary interface is added for each modules, in addition to 3 stories, 3 rhymes and 3 songs

A game with a list of top scores ordered by date ranging from the oldest to the most recent results.

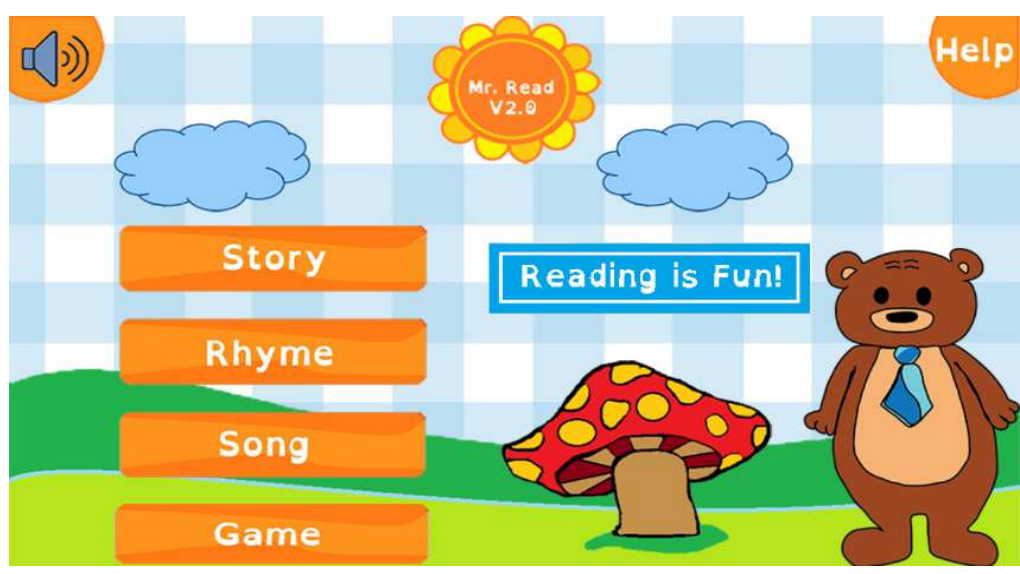

Fig. 1: Main menu of Mr. Read V2.0

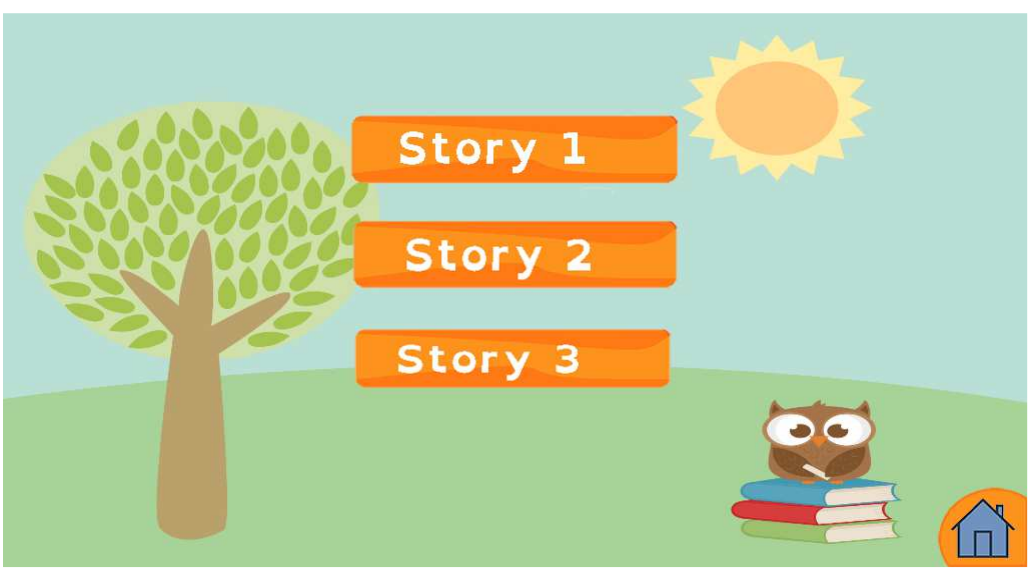

Fig. 2: Menu for story module

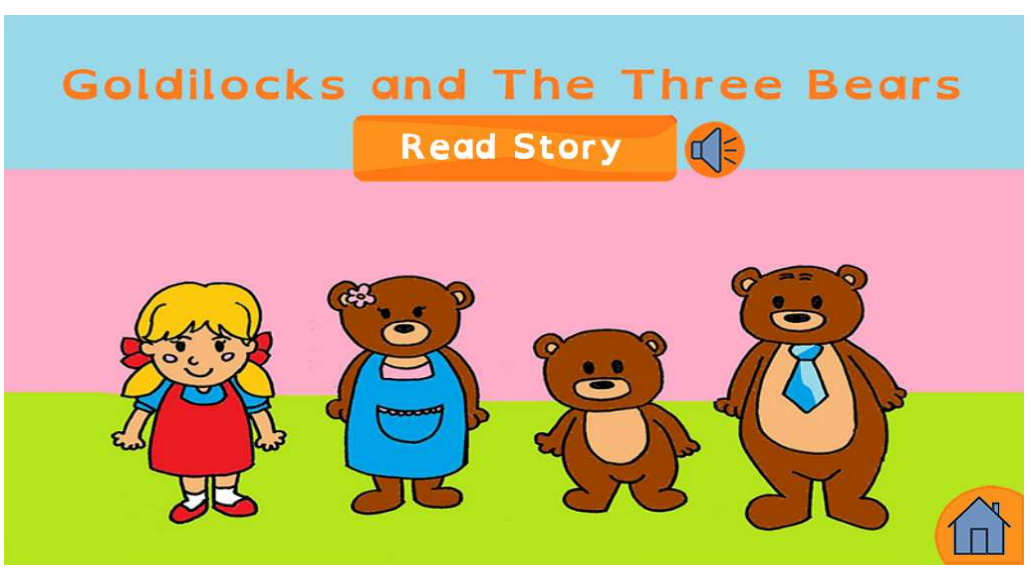

Fig. 3: Main page of story 3 


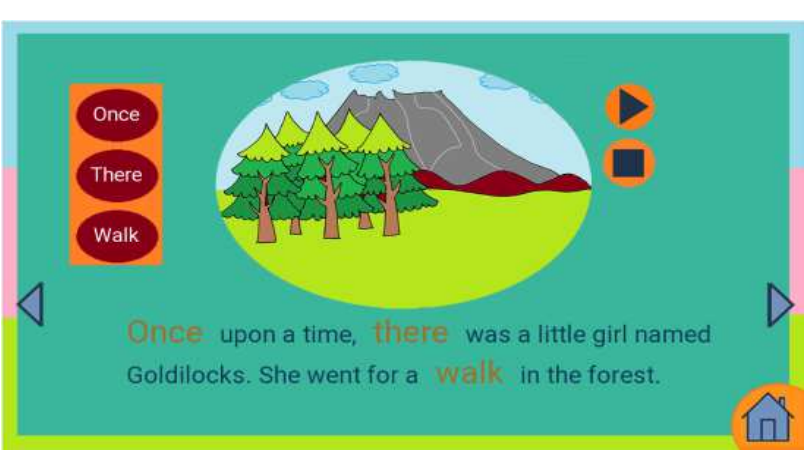

(a)

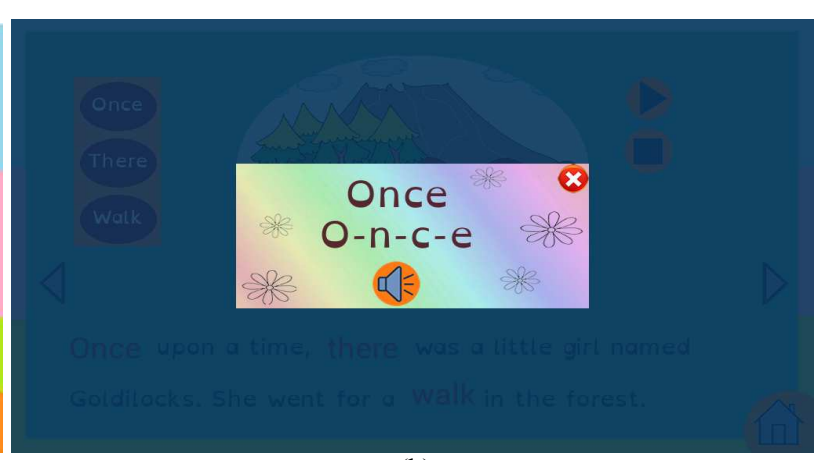

(b)

Fig. 4: (a) Page 1 of story 3 (b) Pop up box of a sight word

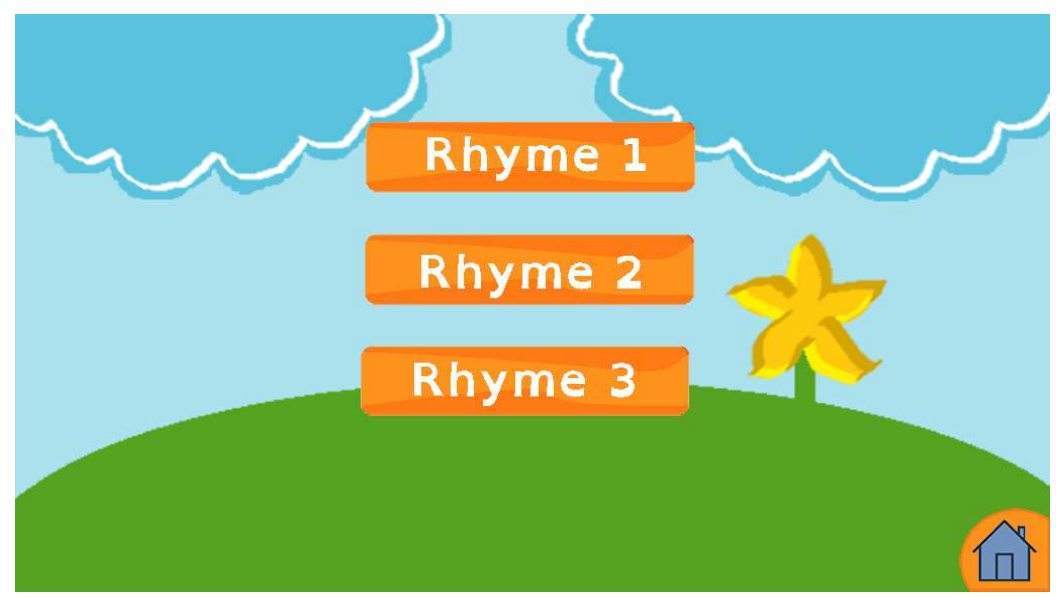

Fig. 5: Menu of rhyme module

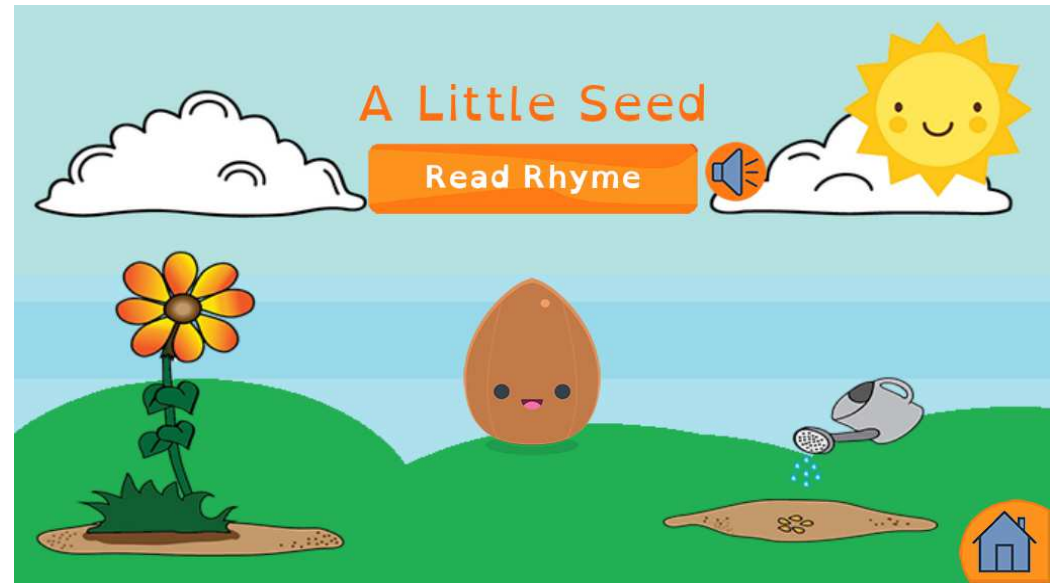

Fig. 6: Main page of rhyme 1

In the main page of Rhyme 1 as shown in Figure 6, the user can tap on the "Guideline button" or button with the speaker image to listen to the rhyme guide. To begin reading the rhyme, the user may tap the "Read Rhyme" button and will direct the user to page shown in Figure 7 above. Afterward, the instruction on how to read the rhyme will play automatically. The user can tap on any of the eight "Rhyme" buttons to listen to the rhyming line by line. At any point when the user needs to read the whole rhyme, the user can tap the button with speaker image at the top right corner of the page.

Figure 8 shows the menu for the song module. There are three different submodules/songs available that are corresponded to the buttons "Song 1", "Song 2" and "Song 
3". For instance, the user may tap on the button "Song 3" and will lead the user to the main page for Song 3 as shown in Figure 9. The instruction to navigate this page is same as demonstrated in Figure 3 and Figure 6 . To begin singing the song, the user may tap the "Let's Sing" button and subsequently lead the user to the page shown in Figure 10.

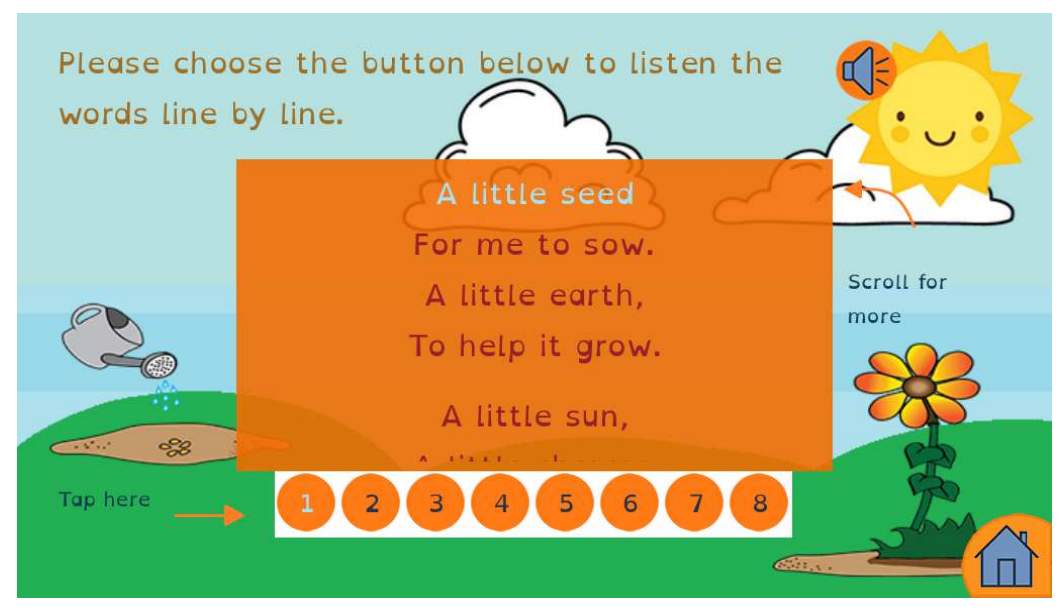

Fig. 7: Next page of rhyme module 1

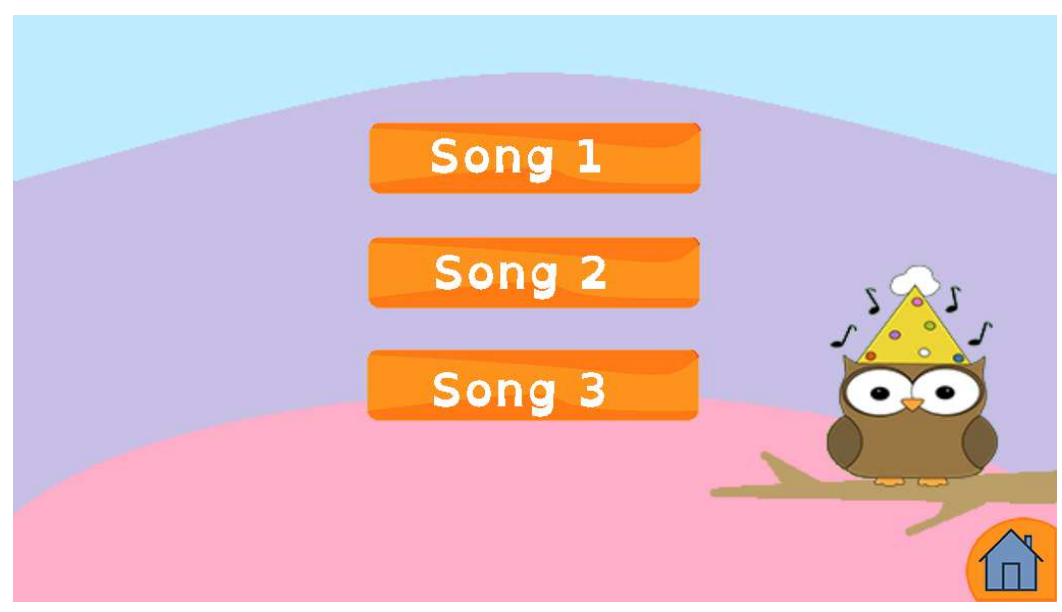

Fig. 8: Menu for song module

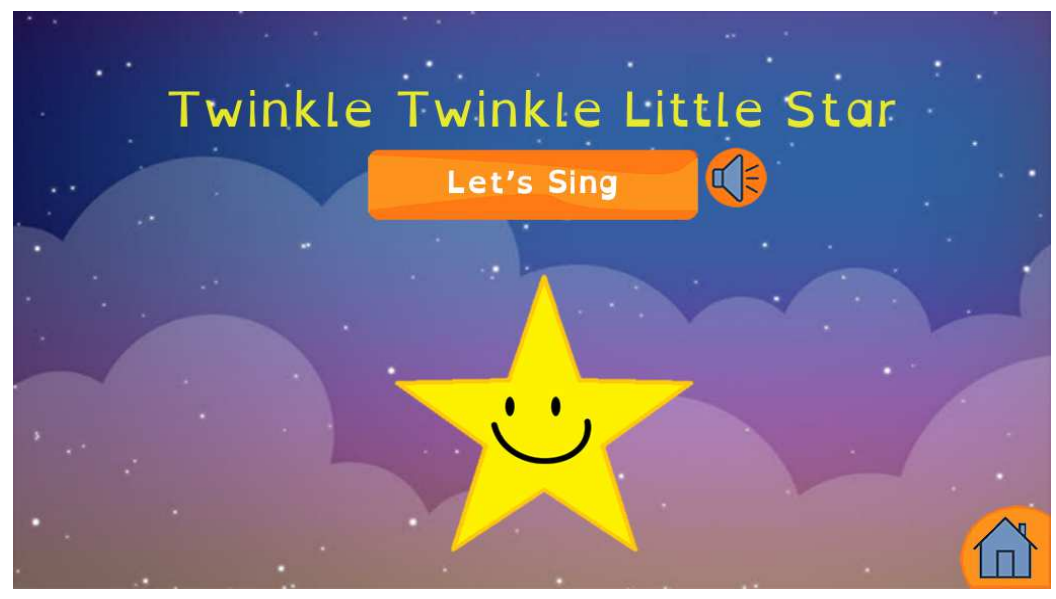

Fig. 9: Main page of song 3 
Figure 10 shows the page of Twinkle Twinkle Little Star song. The user can start singing by tapping on the "Play" button. On the other hand, the user may tap on the "Stop" button if the user wishes to stop at any time.

Figure 11 is the main page for balloon word game, which can be accessed by choosing the Game module at main menu as shown in Figure 1. Instruction on how to play the balloon game will be automatically played. A concise word will be consequently displayed in the balloon before the user begins to play. Then, the user will tap on the correct sight words which appeared in the cloud to match with the sight words displayed in the balloon. There are 10 questions for each game.
Figure 12a shows the score accomplished after completing the game which is shown in Figure. 8. The user able to track the accomplishment by viewing the scoreboard. To access the scoreboard page, the user may tap on the "Scores" button. Figure 12b shows the scoreboard page. The scores are sorted in ascending order along with the date played. Besides, the score is computed in view of the correct answers. The user can close the scoreboard page by tapping on the "Close" button and will be directed back to Figure 12a. The user can re-play the game by tapping on the button "Play" button. Meanwhile, the user can tap on the "Home" button to go back to Mr. Read V2.0 main menu.

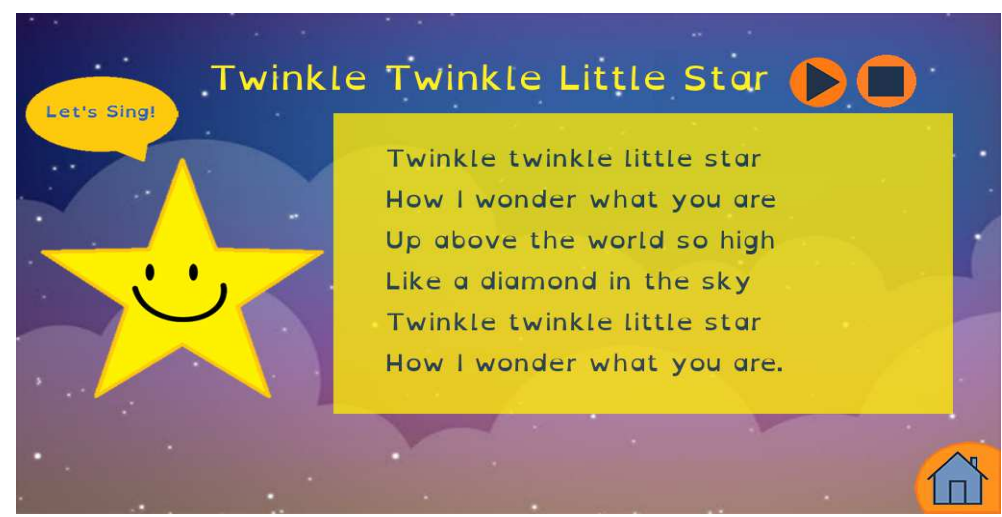

Fig. 10: Next page of song 3

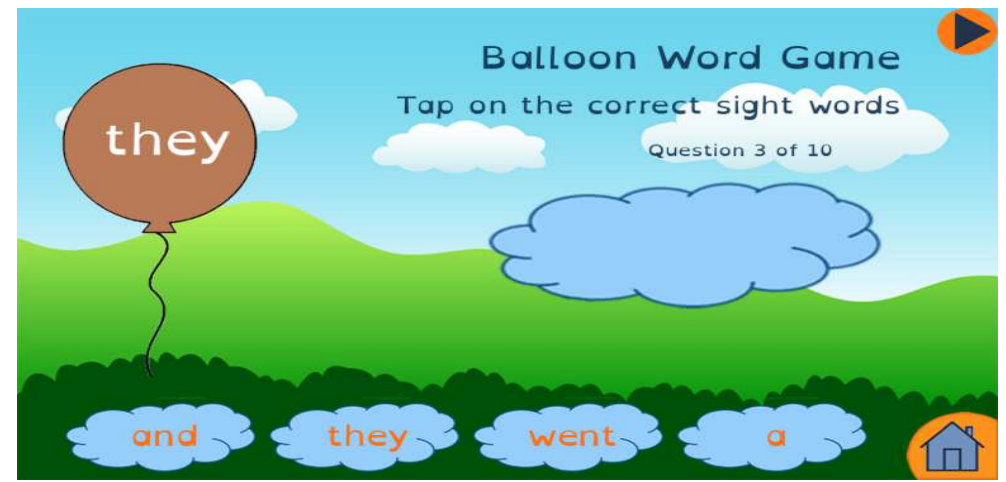

Fig. 11: Main page of game module

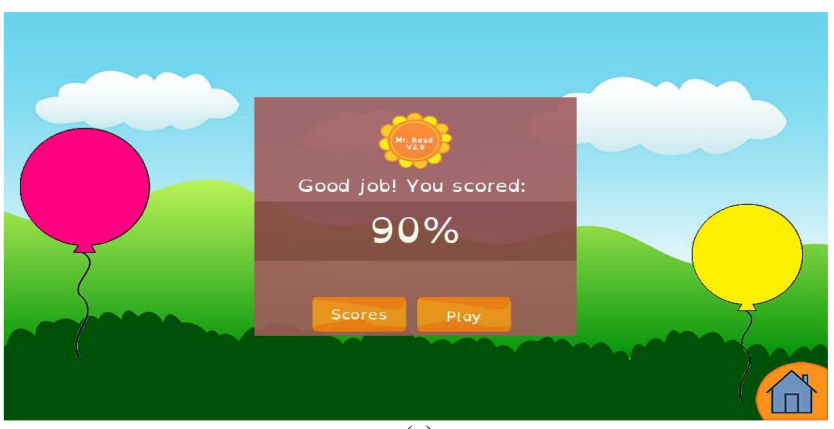

(a)
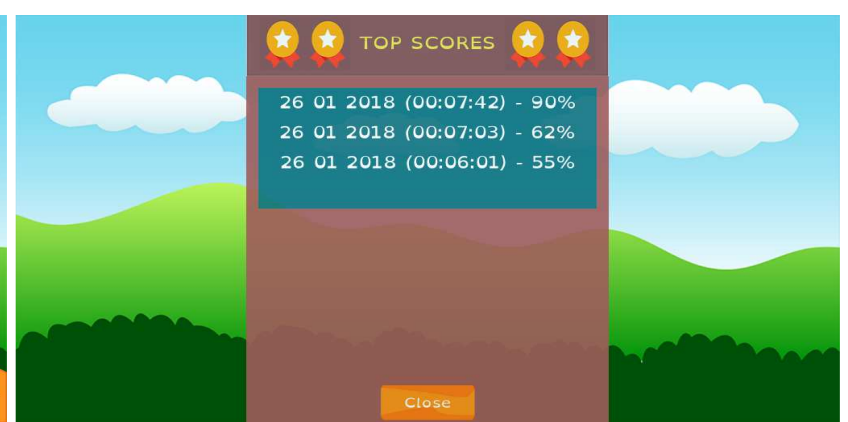

(b)

Fig. 12: (a) Score achieved after completing the game 


\section{Results and Findings}

This section presents the results and findings of the testing sessions of Mr. Read V2.0. The results are presented in two sections: The performance of the eight dyslexic primary school students before and after using the mobile application and the outcome from the usability testing with the dyslexic primary school students, four teachers and two parents.

Figure 13 depicts the effectiveness of Mr. Read V2.0 on the eight dyslexic primary school students. The students' improvement is measured by the average game scores achieved from three sets of quizzes they had taken, which consist of the game scores before reading from any of the modules, game scores after reading Story 1 and game scores after reading Story 2 and 3 in Mr. Read V2.0. Based on the result above, the average scores gradually increase from 69.13 to $97.88 \%$. A notable effect after all three quizzes, five of the eight students showed improvement from having difficulty to spell and sound out words to confidently spelling out the words. Some of the words the that the students have difficulty to pronounce are 'hungry', 'changes', 'learn', 'first', 'egg', 'when' and 'after'. This shows that, with the Story module, the students learn and recognize words more effectively. Other than sight words, one of the features contributed to the students' improvement is the replay button which encourages students to repeatedly learn the words that they felt difficult to pronounce.

From the usability testing with the students, parents and teachers, in view of Figure 14, 13 out of 14 respondents strongly agreed that the mobile application is easy to use and manage. Not only that, 11 out of 14 respondents strongly agreed that all the instructions are exhibited in simple and straightforward language. They can explore the applications effortlessly without much clarification. This demonstrated that the Mr. Read V2.0 is simple and usable. Apart from that, the finding demonstrated that the Mr. Read V2.0 is clear and easy to use for the majority of the respondents.
Figure 15 demonstrates the consequence of $\mathrm{Mr}$. Read V2.0 user interface and multimedia components rating. In view of the outcome, $85.71 \%$ of the respondents are happy with the user interface design, colour and picture utilized. However, in the Story module, one of the respondents disagreed with the user interface because the respondent felt that the colour foundation has smothered the writings, which will make it harder for the children with dyslexia to read. Furthermore, concerning the use of sound, 12 out of 14 respondents have strongly agreed that the sounds used are alluring and the sound used for instruction and narration are suitable and clear.

According to Figure 16,13 out of 14 of the respondents have agreed that the mobile application can assist children with dyslexia in learning and majority respondents agreed that Mr. Read V2.0 encourages children with dyslexia to read. With respect to the viability in learning of sight words which can be referred in Figure 4 indicated all of the respondents with 11 of them are strongly agreed that Mr. Read V2.0 learning approach is effective.

When the response on the efficiency of learning (Figure 16) are compared to the test results of the dyslexic primary school students (Figure 13), the students have shown an increase in game score after reading the first story then followed by the second and third stories. The increased of game scores have shown that Mr. Read V2.0 is effective in helping dyslexic children to improve their reading ability. Likewise, one of the respondents suggested that the dyslexic children should be given the capacity to record themselves sounding out the sight words rather than just showing the sight words. Another suggestion is to add more variety of stories into the story module.

Figure 17 indicates that $93 \%$ of respondents are interested to download this mobile application in future. This demonstrates that Mr. Read V2.0 can be further enriched and marketed. Moreover, 6 out of 14 respondents, who are educators and parents, expressed that the general idea of this mobile application is extraordinary since they typically utilize flash cards to show sight words.

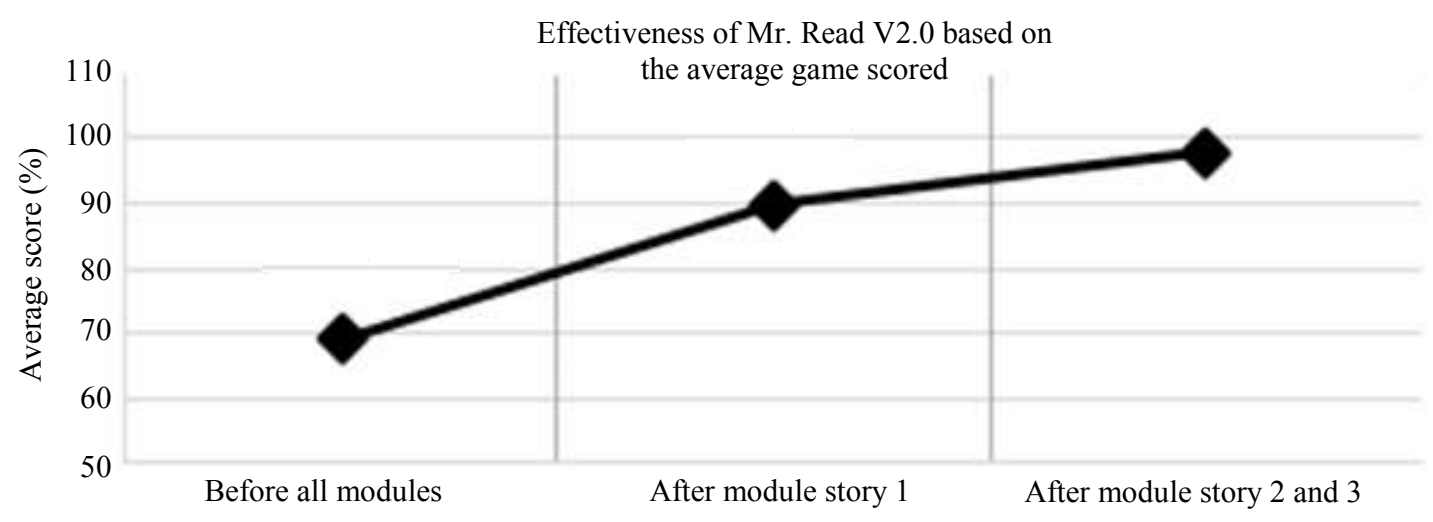

Fig. 13: Results of game scored to evaluate the effectiveness of Mr. Read V2.0 
Mr. Read V2.0 ease of use

Q1. Mr read is easy to use

Q6. Mr read instructions are simple and clear

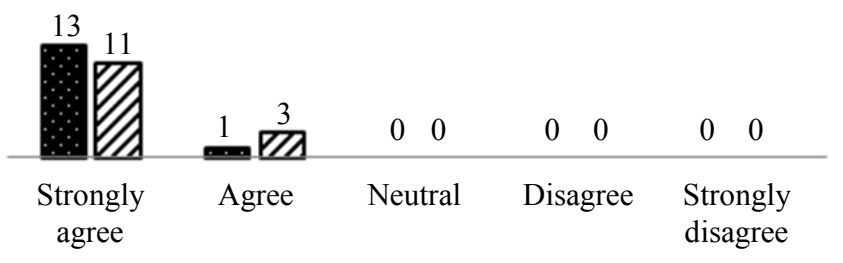

Fig. 14: Mr. Read V2.0 eases of use rating results

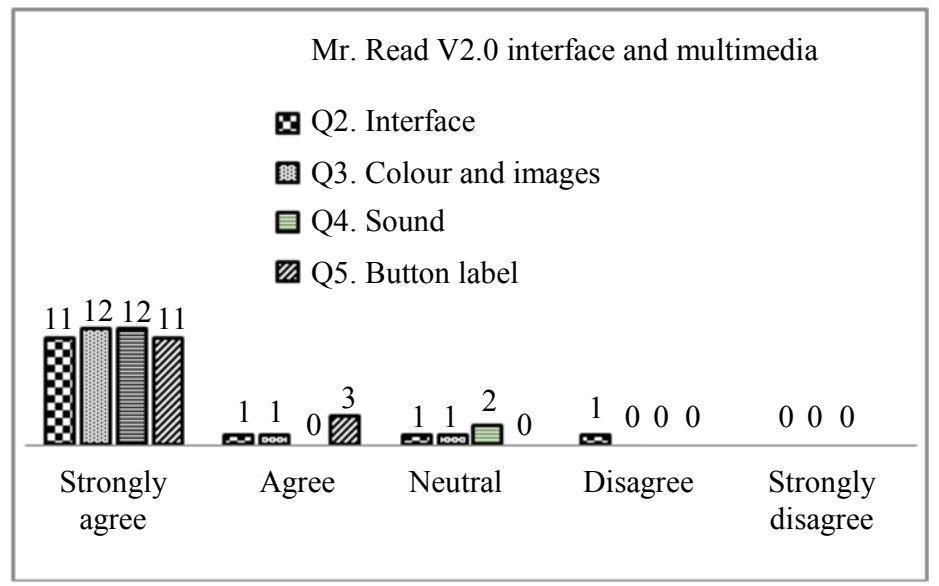

Fig. 15: Mr. Read V2.0 Interface and multimedia elements results

Mr. Read V2.0 efficiency in learning

Q7. Assist user in reading

$\mathbb{Q}$ Q8. Encourage user to read

Q Q9. Effectiveness in learning of sight words

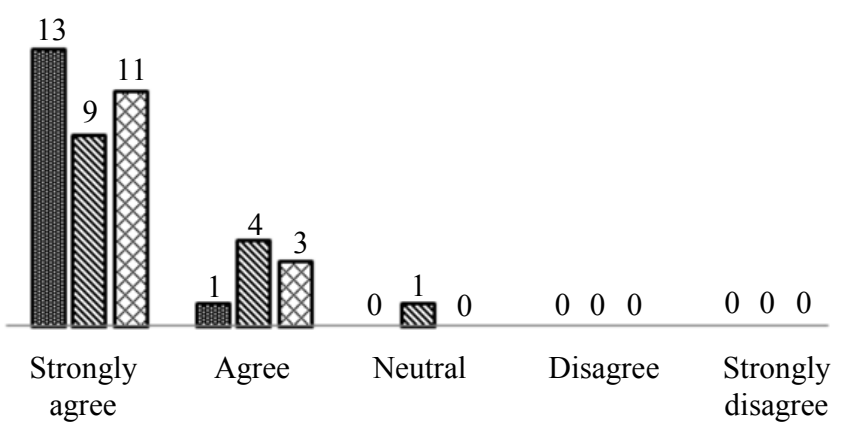

Fig. 16: Mr. Read V2.0 efficiency in learning results 


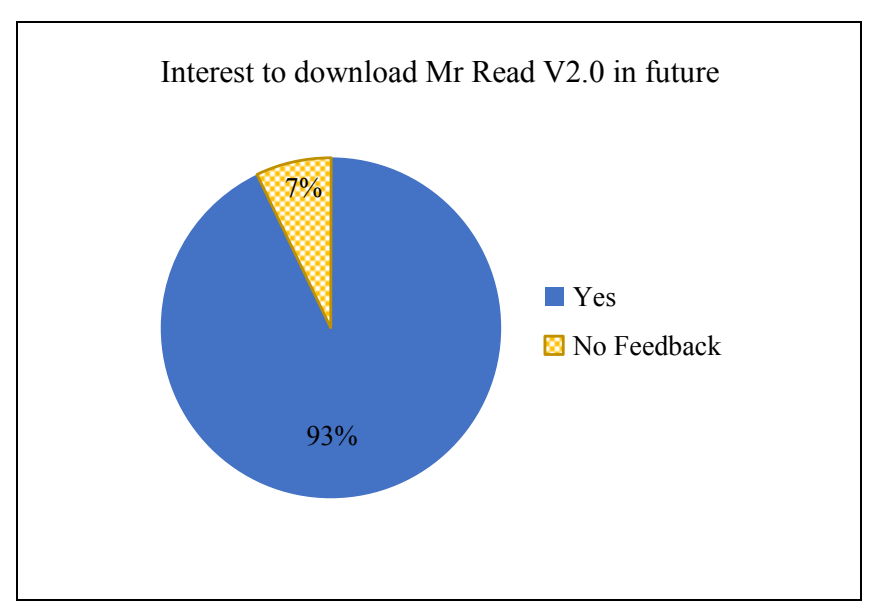

Fig. 17: Results of user satisfaction

\section{Discussion}

This study was conducted to see if sight word instruction integrated into the mobile application has any impact on the overall reading ability of dyslexic primary school students. The main research question for this study is how effective using sight words approach in a mobile application to improve the reading ability of dyslexic students? Throughout this study, two major findings are found which are the sight word instructions through mobile application, has improved the overall reading ability of the children with dyslexia and this has subsequently improved their confidence in reading. These findings indicate that generally, using mobile application as a learning platform to teach sight words is effective in helping dyslexic children to improve their reading skills. Therefore, the enhanced mobile application, Mr. Read V2.0 has the potential as an additional learning tool for the children with dyslexia.

\section{Conclusion}

Throughout the evaluation session, dyslexia primary school students continuously played the game and sang along the song. This demonstrates their interest in the mobile application. This could be partially contributed to the recognizable music and word game that motivate them to continue playing and learning through the application. The high number of positive responses also demonstrates that the upgraded mobile application, $\mathrm{Mr}$. Read V2.0 is effective in developing reading and spelling abilities among dyslexic children. The utilization of sight words in various learning stages can improve their reading ability. The usability and attractive user interface of the Mr. Read V2.0 as far as design, selection of colours, sounds and pictures make children with dyslexia able to explore the mobile application effortlessly. Thus, the objectives of the enhancement of Mr. Read V2.0 have been satisfied and accomplished.
Future works will involve adding more interactive learning features such as an audio record of users' voice so that dyslexic children to replay back and learn to pronounce the sight words at their own pace. Besides, the improvement on mobile application contents will be considered for future work. We strongly encourage adoption of this method as an alternative way to improve reading skill among children with dyslexia.

\section{Acknowledgment}

Authors wish to thank the Dyslexia Association of Sarawak center, including their instructors, dyslexic children and parents and furthermore, Universiti Malaysia Sarawak (UNIMAS). This work was supported under Grant No: F08/SpSTG/1364/16/6.

\section{Author's Contributions}

Noor Hazlini Borhan: Makes substantial contributions in the development, writing and formatting of the manuscript.

Cheah Wai Shiang and Chiu Po Chan: Contributes in the collecting data and analysis of the manuscript.

Hamizan Sharbini, Tan Ping Ping and Rosita Mohamed Othman: Have participated in proofreading and give final approval of the manuscript to be submitted.

Marcella Peter: The research assistant has done the collecting data, development and testing the application.

\section{Ethics}

The authors confirm that this manuscript has not been published elsewhere and that no ethical issues are involved.

\section{Conflict of Interest Declaration}

The author(s) declare(s) that there is no conflict of interest regarding the publication of this manuscript. 


\section{References}

Alghabban, W.G., R.M. Salama and A.H. Altalhi, 2017. Mobile cloud computing: An effective multimodal interface tool for students with dyslexia. Comput. Human Behav., 75: 160-166.

Azmi, A.Z., N.H. Nasrudin, A.W.N. Wan and J.R. Ahmad, 2017. Mobile application to writing skills ability among dyslexic children: CiNTA. J. Fundamental Applied Sci., 9: 195-209.

Borhan, N.H., H. Sharbini, J.A. Ahmadi and P.C. Chiu, 2015. Developing reading skills using sight word reading strategy through interactive mobile gamebased learning for dyslexic children. Int. J. Innovat. Educ. Res.

Bouquett, K.E. and S. Lindsey, 2008. Systematic sight word instruction for reading success: A 35-week program. Scholastic Inc.

Farrell, L. and T. Osenga, 2013. Comparing the dolch and fry high frequency word lists. Readsters, LLC.

Fawcus, M., 2000. Children with Learning Difficulties: A Collaborative Approach to their Education and Management. 1st Edn., Wiley, London, ISBN-10: 1861560184, pp: 334.

Garg, S., 2016. Game based learning in education: The 21 st century pedagogy.
Griffin, S.M. and K.L. Appel, 2016. Reading strategies. Johnson, D., 1971. The dolch list re-examined. Read. Teacher, 24: 449-457.

Lee, S.H., 1999. Usability testing for developing effective interactive multimedia software: Concepts, dimensions and procedures. Educ. Technol. Society, 2: 1-13.

Lyon, G.R., S.E. Shaywitz and B.A. Shaywitz, 2003. A definition of dyslexia. Ann. Dyslexia, 53: 1-14.

McArthur, G., A. Castles, S. Kohnen, L. Larsen and K. Jones et al., 2013. Sight word and phonics training in children with dyslexia. J. Learn. Disabilities.

Meares, O., 1980. Figure/ground, brightness contrast and reading disabilities. Visible Lang., 14: 13-29.

Samsudin, R., 2017. Dyslexia aide (Mobile Learning Application for Dyslexic Kids). Int. J. Software Eng. Technol.

Shiratuddin, N. and S.B. Zaibon, 2011. Designing us experience for mobile game-based learning. Proceedings of the International Conference on User Science and Engineering, Nov. 29-Dec. -1, IEEE Xplore Press, Shah Alam. DOI: 10.1109/iUSEr.2011.6150543 